Ann. Biol. anim. Bioch. Biophys., I973, 13 (2), 225-246.

\title{
INFLUENCE DE LA SUPPLÉMENTATION EN ACIDES AMINÉS SOUFRÉS D'UN ALIMENT D'ALLAITEMENT SUR L'AMINO-ACIDÉMIE ESTIMATION DU BESOIN EN MÉTHIONINE DU VEAU PRÉ-RUMINANT
}

\author{
P. PATUREAU-MIRAND, J. PRUGNAUd et R. PION \\ avec la collaboration technique de Françoise BARRE, \\ Marie-Claude Valluy, A. Selle et M. Sallas \\ Laboratoive d'Étude des Métabolismes, \\ Centre de Recherches de Clermont-Ferrand, I. N. R. A., \\ Theix, 63110 Beaumont
}

\section{RÉSUMÉ}

Afin d'estimer le besoin du Veau pré-ruminant en acides aminés soufrés, nous avons étudié l'influence de la supplémentation d'un aliment d'allaitement par ces acides aminés sur l'aminoacidémie jugulaire du Veau. Au cours de l'expérience $\mathrm{I}$, chacun des 6 veaux recevait pendant des périodes successives de ro jours l'un des 6 régimes à base de poudre de lait enrichie en lysine, thréonine et dont les teneurs en méthionine et cystine (g pour roo $\mathrm{g}$ de matières azotées) étaient respectivement de $: 3,5$ et 0,$9 ; 3,5$ et $\mathrm{r}, 5 ; 3,5$ et 2,$0 ; 4,5$ et 0,$9 ; 4,5$ et 1,$5 ; 4,5$ et 2,0 . Au cours de 1 'expérience 2, chacun des 6 veaux, recevait pendant des périodes de $I_{4}$ jours, l'un des 3 régimes à base de poudre de lait enrichie en lysine, thréonine et arginine dont les teneurs en méthionine et cystine ( $\mathrm{g}$ pour $100 \mathrm{~g}$ de matières azotées) étaient respectivement de :2,6 et 3,0;3,0 et 3,0 3.5 et 3,0 .

L'augmentation de l'apport de méthionine a entraîné une augmentation de la méthioninémie. Celle-ci devenait très élevée lorsque les régimes contenaient plus de $\mathbf{9 , 0 5} \mathrm{g}$ de méthionine par $\mathrm{kg}$ de poudre. L'évolution de la méthioninémie était en relation particulièrement étroite avec la quantité de DL-méthionine synthétique ajoutée ingérée. La supplémentation par des doses croissantes de cystine n'a eu aucune influence sur les paramètres que nous avons étudiés. Le besoin en méthionine du Veau pré-ruminant serait voisin de $0,9 \mathrm{~g}$ pour roo $\mathrm{g}$ d'aliment c'est-à-dire de $3,5 \mathrm{~g}$ pour too $\mathrm{g}$ de matières azotées d'un aliment contenant au moins $0,9 \mathrm{~g}$ de cystine pour $100 \mathrm{~g}$ de matières azotées. Lorsque la teneur du régime en méthionine était de $4,5 \mathrm{~g}$ pour $100 \mathrm{~g}$ de matières azotées, on observait une augmentation de la concentration en la plupart des acides aminés. Cela pourrait reflèter l'effet de l'ingestion d'un excès de méthionine sur les glandes cortico-surrénales. 


\section{IN'TRODUC'TION}

La part des protéines de lait dans les aliments d'allaitement semble devoir diminuer au profit de celle d'autres protéines, moins chères. Or, le Veau pré-ruminant est sensible à la qualité des protéines alimentaires (BLAXTER et WOOD, I952). D'une façon générale, les matières azotées susceptibles d'être utilisées dans les aliments d'allaitement sont pauvres en acides aminés soufrés, mais il est possible d'en envisager la supplémentation par de la DL-méthionine dont le prix n'est pas excessif. C'est ainsi qu'ODORICO (I969) et ROBERT (I97I) ont mis en évidence l'intérêt d'une supplémentation des protéines de lait par de la DL-méthionine, que PORTER et HILI, (I964) ont montré que la supplémentation par la méthionine améliorait les performances de veaux recevant un régime à base de protéines de soja. Les acides aminés soufrés semblent donc être un facteur limitant de l'efficacité des aliments d'allaitement classiques et c'est pourquoi nous nous sommes attachés à la détermination du besoin du Veau pré-ruminant en ces composés. Ce besoin a déjà été étudié chez d'autres espèces et semble se situer entre $5 \mathrm{~g}$ et $7 \mathrm{~g} \mathrm{p}$. Ioo $\mathrm{g}$ de matières azotées alimentaires chez le Rat en croissance et entre 3,0 et $3,5 \mathrm{~g}$ chez le Porc en croissance (FAUCoNNEAU, I967). De plus, depuis les travaux de WOMACK, KEMMERER et ROSE (I937), nous savons que l'acide aminé soufré indispensable est la méthionine. Celle-ci, par une réaction de trans-sulfuration irréversible chez les animaux supérieurs, peut se, transformer en cystéine puis en cystine (TARver et SchmIDT,I939; DU VIGNEAUD Brown et Chandier, I942). Le besoin en méthionine dépend donc de l'apport de cystine dans le régime. Ainsi, Rao et al. (I96I) ont montré que le besoin en acides aminés soufrés pour la croissance du Rat était de $5 \mathrm{~g} \mathrm{p}$. $100 \mathrm{~g}$ de matières azotées et que le besoin pouvait être satisfait soit par l'apport de $5 \mathrm{~g}$ de méthionine soit par l'apport de $5 \mathrm{~g}$ d'un mélange de méthionine et de cystine dans lequel la part minimale de la méthionine était de $32 \mathrm{p}$. Ioo.

Mc LaUghian et Iliman (I967), PAWLAK et Pion (rg68 a), STOCKIAND et al. (I970) chez le Rat, Mitchel et al. (I968 b) chez le Porc, Young et al. (I97I) chez 1'Homme ont montré que l'on pouvait estimer le besoin en un acide aminé indispensable en suivant l'évolution de la concentration en cet acide aminé sous forme libre dans le sang ou le plasma lorsque l'animal ingère des régimes supplémentés par des doses croissantes de cet acide aminé. La présence d'un excès d'un acide aminé dans la ration entraîne, au moins pour certains acides aminés, une augmentation importante de la concentration en cet acide aminé dans le sang. C'est donc en étudiant la concentration en acides aminés libres du sang de veaux recevant des régimes différant par leur teneur en méthionine et en cystine que nous avons tenté de déterminer le besoin en acides aminés soufrés du Veau pré-ruminant. Cette technique que complète l'étude de la croissance et de la consommation, a l'avantage de nous donner des informations sur le métabolisme des acides aminés étudiés et sur celui des autres acides aminés.

\section{MATÉRIEL ET MÉTHODES}

I.es travaux rapportés dans cette publication représentent les résultats de 2 expériences complémentaires. 


\section{I. - Animaux}

Dans les deux expériences, nous avons travaillé avec 6 veaux mâles de la race Française Frisonne Pie Noire âgés d'environ 2 à 3 semaines en début d'expérience. Les animaux étaient logés en cases individuelles sur caillebotis dans un local dont la température était maintenue cons-

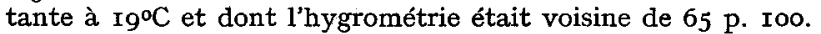

\section{2. - Régimes}

L'aliment de base (Toullec, communication personnelle) était essentiellement constitué de poudre de lait écrémé Spray, réengraissée par du suif (tabl. I). Cet aliment de base a été supplémenté par 0,1 p. roo de lysine et 0,06 p. Ioo de thréonine, et en outre, lors de la deuxième expérience, par $0,35 \mathrm{p}$. Ioo d'arginine.

\section{TABLEAU I}

Composition de l'aliment de base

(p. Ioo $\mathrm{g}$ de poudre)

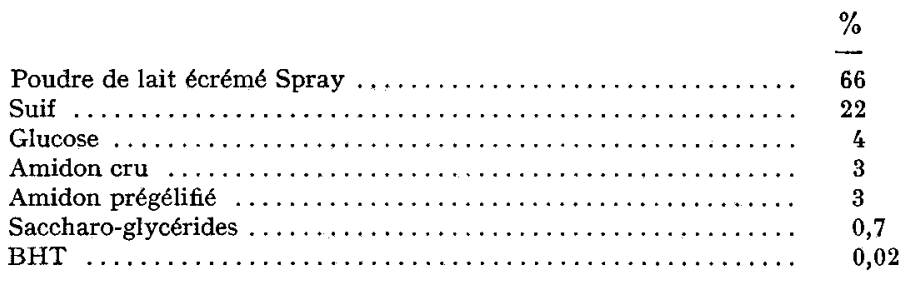

Mélange minéral et vitaminique dont la composition pour $100 \mathrm{~kg}$ de poudre est la suivante :

\begin{tabular}{|c|c|c|c|}
\hline Chlorure de magnésium : $\mathrm{MgCl}_{\mathbf{2}}$, & & & \\
\hline $6 \mathrm{H}_{2} \mathrm{O} \ldots \ldots \ldots \ldots \ldots \ldots \ldots$ & $200 \mathrm{~g}$ & Vitamine $\mathrm{B}_{6}$ & $720 \mathrm{mg}$ \\
\hline Chlorure de zine $\ldots \ldots \ldots \ldots \ldots \ldots$ & $0,4 \mathrm{~g}$ & Vitamine $\mathrm{B}_{12} \ldots \ldots \ldots \ldots \ldots \ldots$ & $5 \mathrm{mg}$ \\
\hline Chlorate de cobalt ...... & $0,06 \mathrm{~g}$ & Acide pantothénique $\ldots \ldots \ldots \ldots \ldots$ & $220 \mathrm{mg}$ \\
\hline Sulfate de manganèse ... & $0,4 \mathrm{~g}$ & Acide nicotinique $\ldots \ldots \ldots \ldots$ & $220 \mathrm{mg}$ \\
\hline Iodure de potassium $\ldots \ldots \ldots \ldots \ldots$ & $0,8 \mathrm{~g}$ & Acide folique $\ldots \ldots \ldots \ldots \ldots \ldots \ldots$ & $100 \mathrm{mg}$ \\
\hline Vitamine $A \ldots \ldots \ldots \ldots \ldots$ & $1200000 \mathrm{UI}$ & Acide para-amino-benzoïque $\ldots \ldots \ldots$ & $990 \mathrm{mg}$ \\
\hline Vitamine $\mathbf{D}_{3} \ldots \ldots \ldots \ldots \ldots$ & $600000 \mathrm{UI}$ & Biotine $\ldots \ldots \ldots \ldots \ldots \ldots \ldots \ldots$ & $75 \mathrm{mg}$ \\
\hline Vitamine $\mathrm{E}^{\circ} \ldots \ldots \ldots$ & $10 \mathrm{~g}$ & Chlorure de choline $\ldots \ldots \ldots \ldots \ldots$ & $180 \mathrm{~g}$ \\
\hline Vitamine $\mathbf{K} \ldots \ldots \ldots \ldots$ & $200 \mathrm{mg}$ & Vitamine $C \ldots \ldots \ldots \ldots \ldots \ldots$ & $10 \mathrm{~g}$ \\
\hline Vitamine $\mathrm{B}_{1} \ldots \ldots \ldots \ldots \ldots$ & $640 \mathrm{mg}$ & Furoxone à 10 p. 100 de furazolidone. & $50 \mathrm{~g}$ \\
\hline Vitamine $\mathrm{B}_{2} \ldots \ldots \ldots \ldots \ldots$ & $300 \mathrm{mg}$ & Chlortétracycline $\ldots \ldots \ldots \ldots \ldots \ldots$ & $6 \mathrm{~g}$ \\
\hline
\end{tabular}

Teneur en énergie brute (valeur calculée) : $510 \mathrm{kcal}$.

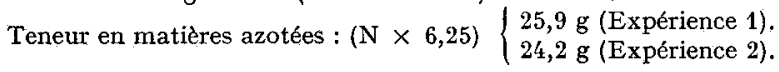

Ces supplémentations ont été calculées pour éviter tout.risque de carence secondaire en ces acides aminés. Nous avions en effet constaté dans une expérience précédente que les concentrations en ces 3 acides aminés dans le sang de veaux nourris au lait étaient relativement faibles.

Les régimes expérimentaux ont été réalisés par addition à l'aliment de base supplémenté en lysine, thréonine et éventuellement en arginine, de différentes quantités d'acides aminés soufrés de façon à obtenir les compositions rapportées dans le tableau 2. 


\section{TABLEAU 2}

Schéma expérimental : répartition des veaux ou des lots en fonction du régime et de la période

\begin{tabular}{|c|c|c|c|c|c|c|c|c|c|c|}
\hline \multirow{2}{*}{\multicolumn{2}{|c|}{$\frac{\text { Expériences }}{\text { Régimes }}$}} & \multicolumn{6}{|c|}{$1 *$} & \multicolumn{3}{|c|}{$2^{* *}$} \\
\hline & & 1 & 2 & 3 & 4 & 5 & 6 & 7 & 8 & 9 \\
\hline $\begin{array}{l}\text { Teneur du régime en } \\
\text { acides aminés soufrés } \\
\text { (g p. } 100 \mathrm{~g} \text { MA) }\end{array}$ & $\begin{array}{c}\text { Méthionine } \\
\text { Cystine }\end{array}$ & $\begin{array}{l}3,5 \\
0,9\end{array}$ & $\begin{array}{l}3,5 \\
1,5\end{array}$ & $\begin{array}{l}3,5 \\
2,0\end{array}$ & $\begin{array}{l}4,5 \\
0,9\end{array}$ & $\begin{array}{l}4,5 \\
1,5\end{array}$ & $\begin{array}{l}4,5 \\
2,0\end{array}$ & $\begin{array}{l}2,6 \\
3,0\end{array}$ & $\begin{array}{l}3,0 \\
3,0\end{array}$ & $\begin{array}{l}3,5 \\
3,0\end{array}$ \\
\hline Périodes & $\begin{array}{r}\text { I } \\
\text { II } \\
\text { III } \\
\text { IV } \\
\text { V }\end{array}$ & $\begin{array}{l}A \\
F \\
E \\
D\end{array}$ & $\begin{array}{l}\text { B } \\
\text { A } \\
\text { F } \\
\text { E }\end{array}$ & $\begin{array}{l}\text { C } \\
\text { B } \\
\text { A } \\
\text { F }\end{array}$ & $\begin{array}{l}\text { D } \\
\text { C } \\
\text { B } \\
\text { A }\end{array}$ & $\begin{array}{l}\mathrm{E} \\
\mathrm{D} \\
\mathrm{C} \\
\mathrm{B}\end{array}$ & $\begin{array}{l}\text { F } \\
\text { E } \\
\text { D } \\
\text { C }\end{array}$ & $\begin{array}{l}\mathrm{A}^{\prime} \\
\mathrm{B}^{\prime} \\
\mathrm{A}^{\prime}\end{array}$ & $\begin{array}{l}A^{\prime} B^{\prime} \\
A^{\prime} B^{\prime}\end{array}$ & $\begin{array}{l}\mathrm{B}^{\prime} \\
\mathrm{A}^{\prime} \\
\mathrm{B}^{\prime}\end{array}$ \\
\hline
\end{tabular}

* Expérience 1 : A, B, C, D, E, F correspondent à chacun des 6 veaux.

** Expérience $2: \mathrm{A}^{\prime} \mathrm{B}^{\prime}$ correspondent à chacun des 2 lots de 3 veaux.

\section{TABLEAU 3}

Plan de rationnement au cours des périodes expérimentales

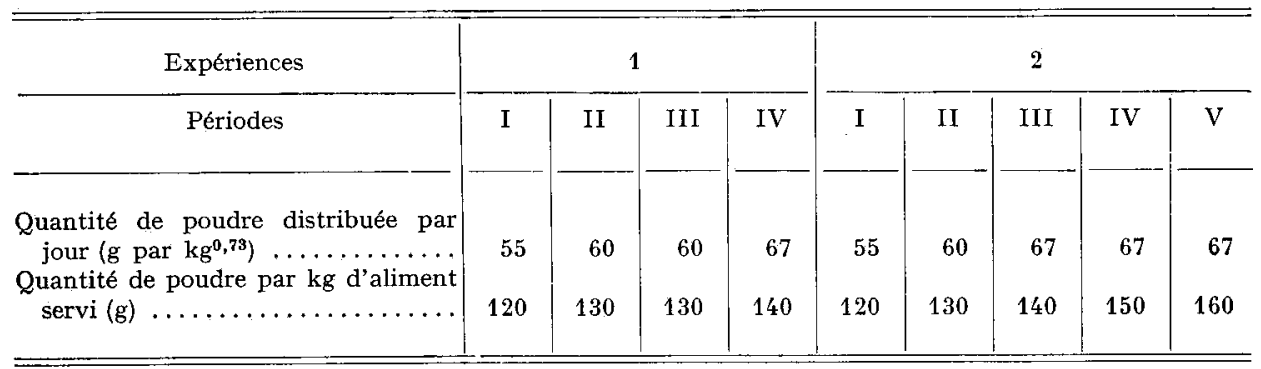

Les régimes expérimentaux étaient préparés en début de période pour toute la période expérimentale. A la quantité d'aliment de base nécessaire à chacun des repas, nous ajoutions une quantité convenable du prémélange d'acides aminés caractéristique de chacun des régimes. Les sacs de polyéthylène contenant l'aliment ainsi supplémenté étaient conservés à $+4^{\circ} \mathrm{C}$ en attendant d'être utilisés. Le lait était reconstitué par addition d'eau à $40^{\circ} \mathrm{C}$ environ aux régimes expérimentaux dans les proportions rapportées dans le tableau 3.

Le plan de rationnement (tabl. 3) pendant les périodes expérimentales a été établi à partir de celui indiqué par Toullec et MATHIEU (I97I). Il tient compte de l'âge et du poids métabolique des animaux. Les veaux recevaient 2 repas par jour.

\section{3. - Schéma expérimental}

Les six régimes de l'expérience I devaient être distribués, au cours de 6 périodes de ro jours à chacun des 6 veaux (A à F), de la façon décrite dans le tableau 2. Nous avons cependant dû arrêter l'expérience à la quatrième période, l'état sanitaire des animaux n'étant plus satisfaisant au cours de la cinquième période. 
Dans l'expérience 2 , nous avons constitué 2 lots $\left(\mathrm{A}^{\prime}\right.$ et $\left.\mathrm{B}^{\prime}\right)$, de trois veaux d'un poids moyen de $53,0 \mathrm{~kg}$ et $53,6 \mathrm{~kg}$ respectivement. Les animaux de chaque lot recevaient pendant chacune des 5 périodes de 14 jours, un des 3 régimes $(7,8$ ou 9) selon le protocole défini dans le tableau 2.

\section{4. - Mesures et techniques analytiques}

\section{Critères zootechniques.}

Les animaux étaient pesés au début de chaque période, le matin avant le repas. Nous avons de plus, enregistré la consommation journalière de chacun des veaux.

\section{Paramètres sanguins.}

Les prélèvements de sang jugulaire étaient effectués les deux derniers jours de chaque période expérimentale, en $\mathbf{2}$ fois, 4 et 5 heures après le repas du matin. Pour les analyses, nous avons choisi, dans la mesure du possible, les échantillons correspondant au jour où les refus au cours du repas du matin avaient été les moins importants. Les échantillons de sang destinés à l'analyse des acides aminés libres étaient recueillis dans l'alcool $95^{\circ}$ froid additionné de $2 \mathrm{p}$. Ioo de thiodiglycol. Les acides aminés libres étaient extraits par $1^{\prime}$ alcool $82^{\circ}$ contenant $2 \mathrm{p}$. roo de thiodiglycol. Les extraits alcooliques étaient purifiés sur résine échangeuse de cations (Amberlite IR I 20). Les acides aminés des échantillons purifiés étaient séparés par chromatographie sur colonne de résine échangeuse d'ions (PAWLAK et PION, 1968 b) selon une version accélérée de la méthode de MOORE, SPACKMAN et STEIN (1958). L'urée était dosée dans le sang total par colorimétrie selon la méthode à la diacétyl monoxime, après défécation à l'acide trichloracétique 2,5 p. Ioo. L'hématocrite était mesuré à la fin de chaque période de l'expérience 2 afin d'estimer l'état d'anémie des veaux. Lorsque l'hématocrite était inférieur à 23, nous avons procédé à des injections intramusculaires de fer pour éviter l'apparition d'anémies prononcées, comme nous en avions observées au cours des cinquième et sixième périodes de l'expérience $\mathbf{I}$.

\section{RÉSULTATS}

\section{I. - Croissance et consommation (tab1. 4 et 5)}

Les vitesses de croissance ont été dans l'ensemble satisfaisantes. Dans l'expérience $I$, les animaux recevant des régimes riches en méthionine (régimes 4,5 , et 6 ) ont eu des vitesses de croissance non significativement différentes de celles des veaux

TABLEAU 4

$V$ itesse de croissance $(\mathrm{g} / \mathrm{j})$

\begin{tabular}{|c|c|c|c|c|c|c|}
\hline \multirow{2}{*}{\multicolumn{2}{|c|}{$\begin{array}{c}\text { Expériences } \\
\text { Régimes }\end{array}$}} & \multicolumn{2}{|c|}{1} & \multicolumn{3}{|c|}{2} \\
\hline & & $\begin{array}{lll}12 & 2 & 3\end{array}$ & 456 & 7 & 8 & 9 \\
\hline \multirow{4}{*}{ Périodes } & I & 733 & 866 & 914 & & 699 \\
\hline & II & 1163 & 1100 & & $\left\{\begin{array}{l}1123^{a} \\
1047 b\end{array}\right.$ & \\
\hline & III & 1080 & 1177 & 1118 & & 1171 \\
\hline & $\begin{array}{r}\text { IV } \\
\text { V }\end{array}$ & 1280 & 1360 & 1209 & $\left\{\begin{array}{l}1114 a \\
1219 b\end{array}\right.$ & 1090 \\
\hline \multicolumn{2}{|c|}{ Moyenne } & 1064 & 1125 & 1080 & 1. 125 & 986 \\
\hline
\end{tabular}

$a:$ Lot $\mathrm{A}^{\prime}$.

$b:$ Lot $\mathrm{B}^{\prime}$. 
nourris avec des régimes moins supplémentés en méthionine (régimes $I, 2,3$ ). Dans 1'expérience 2 , les résultats nous indiquent que les lots n'avaient pas exactement la même vitesse de croissance ; celle du lot $B^{\prime}$ était inférieure de $100 \mathrm{~g} / \mathrm{j}$ environ à celle du lot. $A^{\prime}$ (bien que de façon non significative).

\section{TABLEAU 5}

Niveau de consommation

(g de poudre par jour)

\begin{tabular}{|c|c|c|c|c|c|c|}
\hline \multicolumn{2}{|c|}{ Expériences } & \multicolumn{2}{|c|}{1} & \multicolumn{3}{|c|}{2} \\
\hline \multicolumn{2}{|c|}{ Régimes } & 123 & 456 & 7 & 8 & 9 \\
\hline \multirow{5}{*}{ Périodes } & I & 1137 & 1071 & 1123 & & 969 \\
\hline & II & 1460 & 1384 & & $\left\{\begin{array}{l}1490^{a} \\
1474^{b}\end{array}\right.$ & \\
\hline & III & 1531 & 1586 & 1716 & & 1603 \\
\hline & IV & 1717 & 1917 & & $\left\{\begin{array}{lll}1 & 841 & a \\
1879 & b\end{array}\right.$ & \\
\hline & V & & & 2023 & & 1990 \\
\hline \multicolumn{2}{|c|}{ Moyenne } & 1461 & 1489 & 1621 & 1645 & 1520 \\
\hline \multicolumn{7}{|c|}{$\begin{array}{l:l}a & : \text { Lot } \mathrm{A}^{\prime} . \\
b & : \text { Lot } \mathrm{B}^{\prime} .\end{array}$} \\
\hline
\end{tabular}

Les consommations ont évolué de façon similaire aux vitesses de croissance et les indices de consommation sont extrêmement voisins d'un régime à l'autre et peu différents de I,35 dans l'expérience I et de I,50 dans l'expérience 2 .

\section{2. - Urémie (tabl. 6)}

Elle est très basse, notamment pendant la première période. De plus, dans les. 2 expériences, les animaux recevant les régimes les moins riches en méthionine ont

TABLEAU 6

Urémie

(mg p. too $g$ de sang)

\begin{tabular}{|c|c|c|c|c|c|c|}
\hline \multicolumn{2}{|c|}{ Expériences } & \multicolumn{3}{|c|}{2} & \multicolumn{2}{|c|}{1} \\
\hline Régin & & 7 & 8 & 9 & 123 & 456 \\
\hline Périodes & $\begin{array}{r}\text { I } \\
\text { II } \\
\text { III } \\
\text { IV } \\
\text { V }\end{array}$ & $\begin{array}{r}12,0 \\
23,3 \\
21,4\end{array}$ & $\begin{array}{l}19,0 \\
22,1\end{array}$ & $\begin{array}{l}14,1 \\
22,1 \\
20,5\end{array}$ & $\begin{array}{l}11,8 \\
15,6 \\
19,1 \\
22,3\end{array}$ & $\begin{array}{l}16,6 \\
17,0 \\
17,4 \\
21,0\end{array}$ \\
\hline
\end{tabular}


les urémies les plus basses, surtout au cours de la première période. Les supplémentations en cystine n'ont aucun effet sur l'urémie. L'urémie augmente avec 1'âge.

\section{3. - Amino-acidémie}

Méthionine.

La concentration sanguine en méthionine libre augmente lorsque la quantité de méthionine ingérée par unité de poids métabolique varie dans le même sens (fig. I). Sur les figures 2 et 3 , en coordonnées semi-logarithmiques, il apparaît que la courbe de l'évolution de la teneur en méthionine libre du sang en fonction des quantités de méthionine ingérées est d'allure exponentielle. La méthioni-

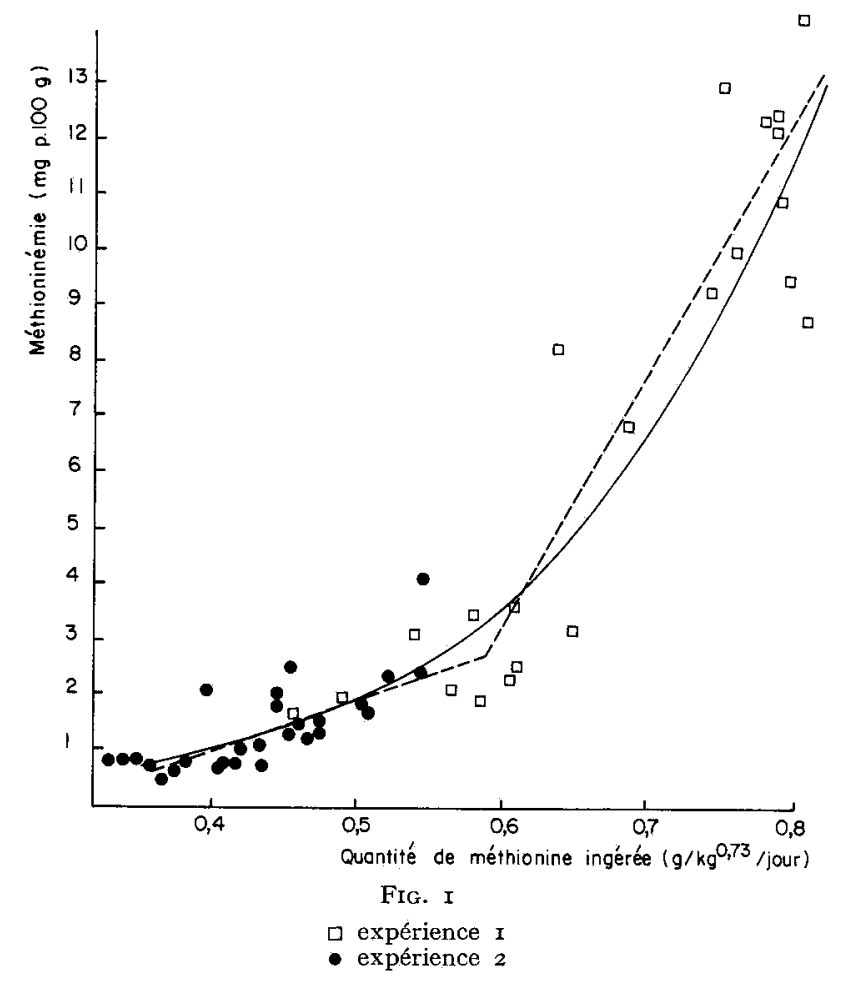

némie dépend très étroitement de la quantité de DL-méthionine synthétique ajoutée et ingérée par unité de poids métabolique et par jour (fig. 2). Le coefficient de corrélation $(r=0,97)$ qui existe entre ces 2 groupes de données est significativement différent $(\mathbf{P}<0,05)$ de celui $(r=0,94)$ qui exprime la liaison entre la méthioninémie et la quantité de méthionine totale ingérée par unité de poids métabolique et par jour (fig. 3).

Enfin, les sangs des veaux qui recevaient des régimes supplémentés par la même quantité de méthionine, mais des quantités différentes de cystine (régimes 9, I, 2, 3 

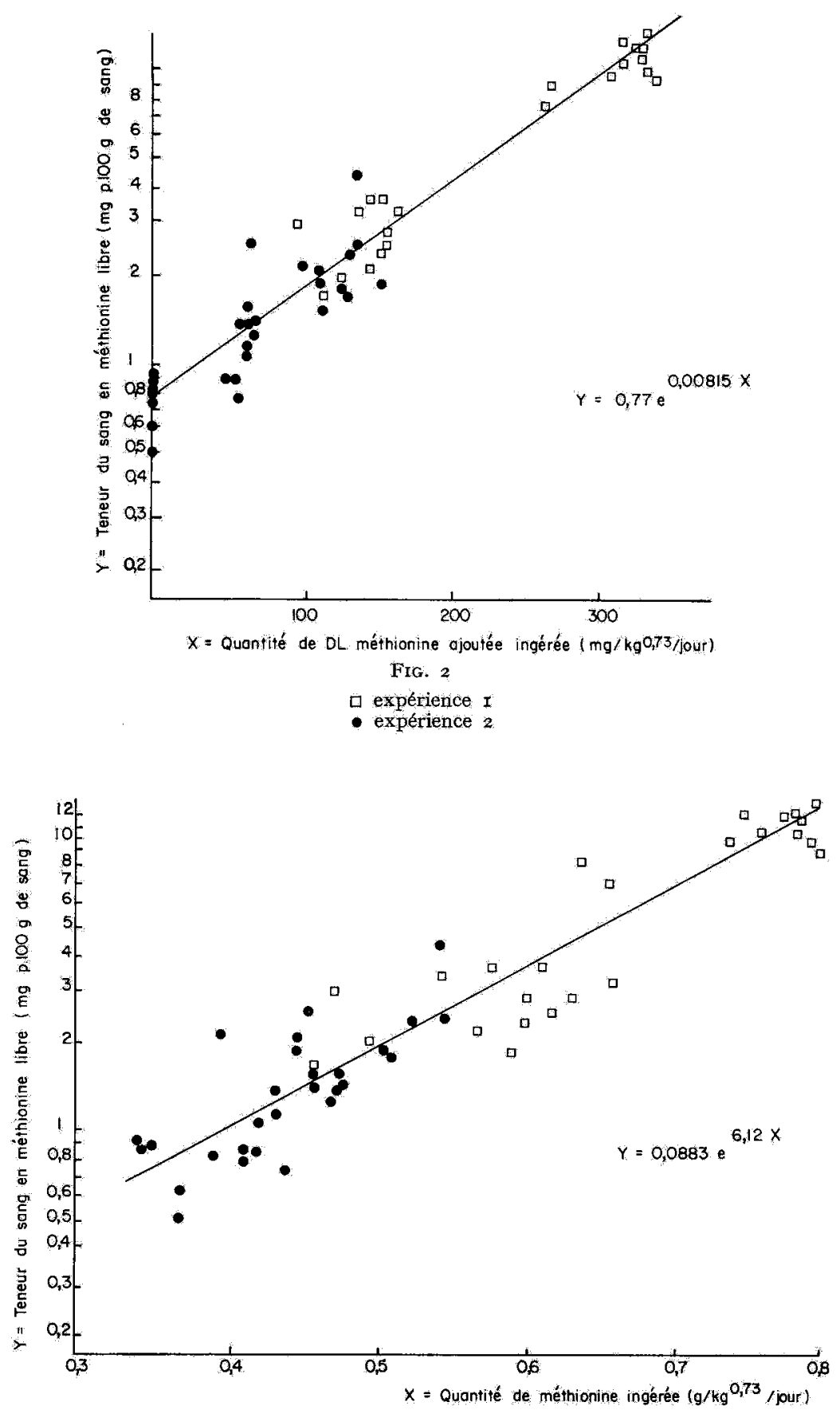

FIG. 3

$\square$ expérience I

- expérience 2 


\begin{tabular}{|c|c|c|c|c|c|}
\hline 0 & 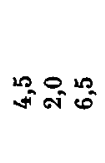 & 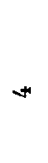 & 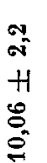 & 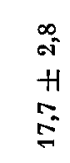 & $\begin{array}{l}\overrightarrow{7} \\
+ \\
\overrightarrow{1}\end{array}$ \\
\hline 10 & +8 & + & 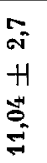 & $\begin{array}{l}\stackrel{9}{-} \\
\text { H } \\
\text { sa }\end{array}$ & \begin{tabular}{l}
0 \\
0 \\
+ \\
\multirow{g}{\sigma}{}
\end{tabular} \\
\hline+ & Lo & + & 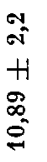 & $\begin{array}{l}\infty \\
- \\
H \\
0 \\
0\end{array}$ & $\begin{array}{l}\infty \\
-1 \\
+ \\
\infty \\
o \\
\sigma\end{array}$ \\
\hline 0 & $\begin{array}{lll}10 \\
\cos ^{2}\end{array}$ & $\sigma$ & $\begin{array}{l}\infty \\
0 \\
+ \\
\text { - } \\
\text { ণิ } \\
\text { जे }\end{array}$ & 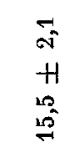 & 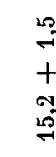 \\
\hline$\infty$ & की & 4 & 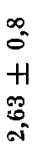 & $\begin{array}{l}0 \\
\text { O } \\
H \\
0 \\
0\end{array}$ & $\begin{array}{l}\infty \\
0 \\
+ \\
\infty \\
10 \\
n\end{array}$ \\
\hline N & 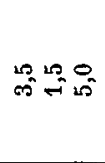 & 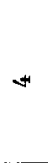 & $\begin{array}{l}0 \\
0 \\
H \\
0 \\
0 \\
i\end{array}$ & $\begin{array}{l}10 \\
\text { o } \\
H \\
+1 \\
\infty \\
\infty\end{array}$ & $\begin{array}{l}20 \\
+ \\
0 \\
5\end{array}$ \\
\hline$r$ & 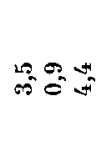 & $\$$ & 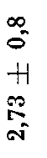 & $\begin{array}{l}\infty \\
-1 \\
+1 \\
0 \\
5\end{array}$ & $\begin{array}{l}0 \\
+ \\
+\end{array}$ \\
\hline$\propto$ & 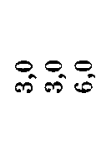 & $\stackrel{9}{\sim}$ & $\begin{array}{l}10 \\
0 \\
+1 \\
0 \\
0 \\
01 \\
-1\end{array}$ & $\begin{array}{l}\overrightarrow{0} \\
+1 \\
\vec{H} \\
\overrightarrow{5}\end{array}$ & $\begin{array}{l}\sigma \\
+ \\
+ \\
0 \\
0\end{array}$ \\
\hline r & 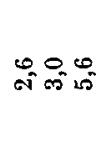 & $\infty$ & $\begin{array}{l}\overrightarrow{5} \\
H \\
\therefore \\
\therefore\end{array}$ & 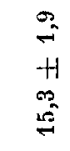 & $\frac{5}{7}$ \\
\hline \multirow[t]{2}{*}{ 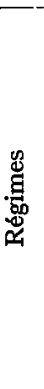 } & \multirow{2}{*}{ 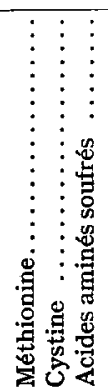 } & \multirow[t]{2}{*}{ 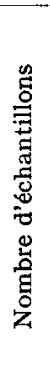 } & 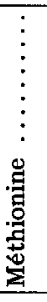 & 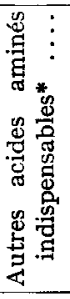 & 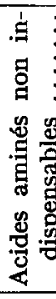 \\
\hline & & & & 品 & \\
\hline
\end{tabular}


ou $4,5,6)$, ont des teneurs voisines en méthionine libre (tab1. 7). Il semblerait donc que la teneur du sang en méthionine libre soit indépendante du niveau des supplémentations en cystine que nous avons effectuées. C'est ce qui explique que chez les veaux recevant des régimes dont la teneur en acides aminés soufrés est comparable (régimes 7,3 et 4 ou régimes 8 et 5 ou régimes 9 et 6 ), la méthioninémie puisse être extrêmement différente selon la teneur en méthionine de la ration.

Les variations de la méthioninémie en fonction de la quantité de méthionine ingérée nous permettent alors de préciser le besoin du Veau pré-ruminant en cet acide aminé. En effet, on peut schématiquement décomposer l'augmentation exponentielle de la méthioninémie en deux phases (fig. I). Lorsque la quantité de méthionine ingérée reste inférieure à $0,58 \mathrm{~g} / \mathrm{kg}^{0,73} / \mathrm{j}$, la méthioninémie augmente relativement lentement. Si la quantité de méthionine ingérée est supérieure, l'accumulation est beaucoup plus prononcée. Donc, à l'ingestion journalière de $0,5^{8} \mathrm{~g}$ de méthionine par unité de poids métabolique semble correspondre une utilisation optimale de la méthionine alimentaire avec les animaux et les régimes étudiés.

\section{Autres acides aminés.}

Cystine.

Nous n'avons pas extrait des quantités mesurables de cystine libre du sang des veaux, même lorsqu'ils recevaient des régimes fortement supplémentés.

\section{Cystathionine.}

Une des particularités de 1'aminogramme du sang de Veau est la présence d'un petit pic de cystathionine. Les teneurs en cystathionine qui semblent assez peu variables n'ont pu être mesurées avec précision.

\section{Acides aminés indispensables.}

Nous avons considéré comme indispensables pour le Veau pré-ruminant tous les acides aminés qui le sont pour le Rat en croissance.

Les variations de la somme des concentrations en acides aminés indispensables sont peu importantes (tabl. 7). Cependant, les teneurs en acides aminés aromatiques, thréonine et dans une certaine mesure lysine et histidine ont tendance à être plus élevées dans le sang des veaux consommant les régimes les plus riches en méthionine, alors que les concentrations des acides aminés à chaîne ramifiée varient très peu (tabl. 8).

Les différents niveaux de supplémentation en cystine n'ont eu aucune influence notable sur les concentrations sanguines des autres acides aminés indispensables, comme le montrent les écarts-types relativement constants des résultats, qu'ils correspondent à un ou plusieurs régimes plus ou moins enrichis en cystine (tab1. 8).

Le rapport des teneurs sanguines en tyrosine à celles en phénylalanine est relativement constant et voisin de $r, 43$.

Les concentrations du sang en arginine pendant les expériences I et 2 , étaient respectivement de $1,6 \pm 0,6$ et $2,0 \pm 0,3 \mathrm{mg}$ pour Ioo $\mathrm{g}$ de sang. Cette différence significative $(\mathrm{P}<0,0 \mathrm{r})$ reflète la différence de composition des régimes de base.

\section{Acides aminés non indispensables.}

Sur le tableau 7 , on voit que la concentration en acides aminés non indispensables du sang s'élève lorsque la teneur du régime en méthionine augmente. 
Cette élévation est le reflet de l'augmentation plus ou moins importante de la concentration des divers acides aminés non indipensables dans le sang.

Cela est particulièrement net dans le cas de la glutamine (十 asparagine), un peu moins avec la proline, la sérine et la glycine (tabl. 8). Par contre, nous obser-

\section{TABLEAU 8}

Teneur du sang de veau (mg $\mathrm{p}$. Ioo $\mathrm{g}$ de sang) en certains acides aminés libres

(moyenne \pm écart type $S_{x}$ )

\begin{tabular}{|c|c|c|c|c|c|}
\hline Régimes & 7 & 8 & $9,1,2,3$ & $4,5,6$ & \multirow{3}{*}{$\begin{array}{c}\text { Degré de } \\
\text { signification } \\
\quad\left({ }^{2}\right)\end{array}$} \\
\hline $\begin{array}{l}\text { Teneur des regimes } \\
\text { en méthionine } \\
\text { (g p. } 100 \mathrm{MA} \text { ) }\end{array}$ & 2,6 & 3,0 & 3,5 & 4,5 & \\
\hline Nombre d'échantillons & 9 & 12 & 21 & 12 & \\
\hline Thréonine $\ldots \ldots \ldots \ldots$. & $1,31 \pm 0,16$ & $1,48 \pm 0,18$ & $1,50 \pm 0,27$ & $1,84 \pm 0,23$ & ** \\
\hline Ac. aminés aromatiques ... & $2,12 \pm 0,34$ & $2,49 \pm 0,38$ & $2,39 \pm 0,40$ & $2,71 \pm 0,33$ & ** \\
\hline Lysine $\ldots \ldots \ldots \ldots \ldots \ldots$ & $2,25 \pm 0,41$ & $2,63 \pm 0,28$ & $2,62 \pm 0,43$ & $2,75 \pm 0,40$ & * \\
\hline Histidine $\ldots \ldots \ldots$ & $1,79 \pm 0,31$ & $2,06 \pm 0,33$ & $2,03 \pm 0,28$ & $2,18 \pm 0,30$ & * \\
\hline Valine.....$\ldots \ldots$ & $2,88 \pm 0,69$ & $3,02 \pm 0,52$ & $2,77 \pm 0,43$ & $2,79 \pm 0,62$ & NS \\
\hline Isoleucine $\ldots \ldots \ldots \ldots$ & $1,28 \pm 0,25$ & $1,40 \pm 0,27$ & $1,26 \pm 0,19$ & $1,16 \pm 0,30$ & NS \\
\hline Leucine $\ldots \ldots \ldots \ldots$. & $1,98 \pm 0,44$ & $2,15 \pm 0,43$ & $1,98 \pm 0,29$ & $1,97 \pm 0,48$ & NS \\
\hline Sérine .. & $1,27 \pm 0,23$ & $1,43 \pm 0,22$ & $1,28 \pm 0,16$ & $1,65 \pm 0,34$ & * \\
\hline Glycine..$\ldots \ldots \ldots$ & $2,61 \pm 0,30$ & $2,86 \pm 0,40$ & $2,58 \pm 0,37$ & $2,89 \pm 0,35$ & NS \\
\hline $\begin{array}{l}\text { Glutamine } \\
\left(+ \text { Asparagine }\left({ }^{1}\right)\right) .\end{array}$ & $2,00+0,55$ & $2,47 \pm 0,46$ & $3,05+1,16$ & $4,44 \pm 0,75$ & $* *$ \\
\hline Acide glutamique ... & $2,12 \pm 0,47$ & $2,17 \pm 0,55$ & $2,17 \pm 0,42$ & $2,42 \pm 0,41$ & NS \\
\hline Alanine . . . . . . . . . & $2,01 \pm 0,31$ & $2,48 \pm 0,49$ & $2,25 \pm 0,51$ & $2,76 \pm 0,51$ & $* *$ \\
\hline Proline $\ldots \ldots \ldots \ldots$. & $1,81 \pm 0,53$ & $1,95 \pm 0,31$ & $1,92 \pm 0,38$ & $2,52 \pm 0,30$ & *** \\
\hline Citrulline + Ornithine ... & $2,15 \pm 0,51$ & $2,95 \pm 0,64$ & $2,51 \pm 0,45$ & $2,42 \pm 0,34$ & NS \\
\hline
\end{tabular}

(1) Résultats exprimés en mg de glutamine.

( $\left.{ }^{2}\right)$ Degré de signification statistique des différences entre les régimes 7 et 4, 5, 6 : $* * \mathrm{P}<0,01 \quad * \mathrm{P}<0,05$.

vons une légère diminution de la somme des concentrations en acides aminés non indispensables lorsque dans le régime le taux de cystine augmente, celui de la méthionine restant constant.

\section{DISCUSSION}

\section{I. - Animaux}

De façon à minimiser les risques d'accidents sanitaires, nous avons travaillé sur des animaux qui étaient déjà assez lourds en début d'expérience $(52,7 \mathrm{~kg})$. En fait, l'état sanitaire des animaux a été satisfaisant. C'est seulement au cours de la 
cinquième période de l'expérience I que nous avons constaté des diarrhées fréquentes, une baisse de la consommation et du gain de poids moyen journalier. Cela nous a conduit à supprimer la cinquième et la sixième période de l'expérience $I$.

\section{2. - Régimes}

L'addition de quantités variables d'acides aminés selon le régime n'a entraîné que des variations du taux protéique des régimes inférieures à $2 \mathrm{p}$. Ioo. Par contre, l'écart est plus important entre le taux protéique moyen des régimes expérimentaux de l'expérience $\mathrm{I}(26,4 \mathrm{p}$. Ioo de la poudre) et celui des régimes expérimentaux de l'expérience $2(24,5 \mathrm{p}$. Ioo de la poudre). Cela est une conséquence de la différence de composition des aliments de base (tabl. I). Cependant, nous ne pensons pas que cela ait eu une importance considérable sur les résultats.

\section{3. - Prélèvements}

Nous avons choisi les modalités de prélèvement de sang en fonction des résultats de l'étude des variations de l'aminoacidémie du Veau pré-ruminant après le repas (Patureau-Mirand, Prugnaud et Pion, I97I). Lorsque nous prélevons 4 et 5 heures après le repas, l'aminoacidémie tend vers un maximum. De plus, le fait de prélever en 2 temps limite les effets de la variabilité importante de la vidange de la caillette.

\section{4. - Traitement des échantillons}

Le sang est recueilli dans 1'éthanol $95^{\circ}$ froid de façon à fixer immédiatement les échantillons. L'alcool est additionné de $2 \mathrm{p}$. Ioo de thiodiglycol afin de protéger de l'oxydation les acides aminés soufrés (PION, PRUGNaUd et RÉRAT, I970). L'analyse porte sur le sang total pour les mêmes raisons que celles développées par PIoN, FAUCONNEAU et RÉRAT (I964).

L'absence de cystine en quantité mesurable dans nos échantillons purifiés ne semble pas être due à la technique de purification puisque l'on retrouve quantitativement la surcharge de cystine ajoutée à un échantillon de sang. Il se pourrait que les quantités de cystine libre dans le sang soient très faibles, notamment parce que la cystine circulante se trouverait liée à des protéines sanguines et ne serait pas extraite par 1'éthanol.

\section{5. - Protocole}

Il importe de savoir s'il y a eu un effet du régime de la période précédente sur les paramètres sanguins observés pendant la période en cours.

Pour cela, nous avons comparé (tabl. 9) l'effet sur la méthioninémie des teneurs en méthionine des régimes consommés au cours de la période qui précède celle du prélèvement. Dans aucun cas, nous n'observons de différence. Cependant, la méthioninémie est plus faible au cours de la première période que pendant les périodes ultérieures, aussi bien pour les animaux recevant les régimes les plus supplémentés (régimes $4,5,6$ ) que ceux qui le sont moins (régimes $I, 2,3$ ) (tabl. 9). Il se pourrait que cela soit la conséquence d'une consommation de méthionine par jour et par $\mathrm{kg}$ de poids métabolique inférieure de I 2 p. Ioo pendant cette période à celle des autres 
périodes. Cela est peut être aussi à relier aux besoins sans doute plus élevés des très jeunes animaux ou au fait qu'avant la première période, l'aliment distribué n'était pas supplémenté.

Dans l'expérience 2, pour mieux maîtriser ce facteur, nous avons allongé les périodes expérimentales de Io à I4 jours et prévu 2 périodes (périodes II et IV) pendant lesquelles les animaux recevaient le même régime (régime 8 ) dont la teneur en méthionine est supérieure ou inférieure à celle des régimes 7 et 9 qui étaient consommés pendant la période précèdant celle du prélèvement (tabl. 9).

\section{TABLEAU 9}

Infuence du niveau de supplémentation pendant la période précédente sur la méthioninémie pendant la période en cours

(mg p. Ioo g de sang)

\begin{tabular}{|c|c|c|c|c|}
\hline \multicolumn{5}{|c|}{ Expérience : 1} \\
\hline $\begin{array}{l}\text { Régimes pendant la } \\
\text { période en cours }\end{array}$ & \multicolumn{2}{|c|}{$1,2,3$} & \multicolumn{2}{|c|}{$4,5,6$} \\
\hline $\begin{array}{l}\text { Régimes pendant la } \\
\text { période précédente }\end{array}$ & $1,2,3$ & $4,5,6$ & $1,2,3$ & $4,5,6$ \\
\hline $\begin{array}{l}\text { Nombre d'échantillons } \\
\text { Methioninémie }\end{array}$ & $\begin{array}{c}4 \\
3,02\end{array}$ & $\begin{array}{c}6 \\
3,03\end{array}$ & $\begin{array}{c}4 \\
11,47\end{array}$ & $\begin{array}{c}6 \\
11,53\end{array}$ \\
\hline
\end{tabular}

Expérience : 2

\begin{tabular}{|c|c|c|c|c|}
\hline $\begin{array}{l}\text { Régime pendant la } \\
\text { période en cours : }\end{array}$ & \multicolumn{2}{|c|}{ Période 2} & \multicolumn{2}{|c|}{ Période 4} \\
\hline $\begin{array}{l}\text { Régimes pendant la } \\
\text { période précédente }\end{array}$ & 7 & 9 & 7 & 9 \\
\hline $\begin{array}{l}\text { Nombre d'échantillons } \\
\text { Méthioninémie }\end{array}$ & $\begin{array}{c}3 \\
1,30\end{array}$ & $\begin{array}{c}3 \\
1,25\end{array}$ & $\begin{array}{c}3 \\
1,13\end{array}$ & $\begin{array}{r}3 \\
1,45\end{array}$ \\
\hline
\end{tabular}

Enfin, sur un animal qui recevait un des régimes riches en méthionine de l'expérience I $(4,5 \mathrm{~g}$ de méthionine pour Ioo $\mathrm{g}$ de matières azotées), nous avons étudié la cinétique de la décroissance de la teneur du sang en méthionine lorsqu'on arrête la supplémentation. Avant l'arrêt de la supplémentation, la méthioninémie était de Io,48 mg pour Ioo $\mathrm{g}$ de sang ; trois jours après, elle était de $2,8 \mathrm{I} \mathrm{mg}$ et 5 jours après, elle était de $0,70 \mathrm{mg}$, valeur caractéristique de la méthioninémie de veaux nourris avec un lait non supplémenté.

Il ne semble donc pas que dans l'une ou l'autre expérience, il y ait eu influence du traitement de la période précédente sur les résultats de la période en cours. 


\section{6. - Besoin en acides aminés soufrés}

Nous avons estimé que, lorsque l'alimentation permettait une ingestion de méthionine supérieure à $0,58 \mathrm{~g} / \mathrm{kg}^{0,73}$, le régime était déséquilibré parexcès de méthionine, ce qui se traduisait par une méthioninémie moyenne supérieure à $2,6 \mathrm{mg}$ pour roo $\mathrm{g}$ de sang. Donc, à une méthioninémie moyenne de $2,6 \mathrm{mg}$ correspond la satisfaction du besoin en méthionine des animaux étudiés pour les régimes utilisés.

Si nous considérons l'évolution de la méthioninémie en fonction de la teneur du régime en méthionine (fig. $4 a$ ), nous voyons que celle-ci est optimale lorsque
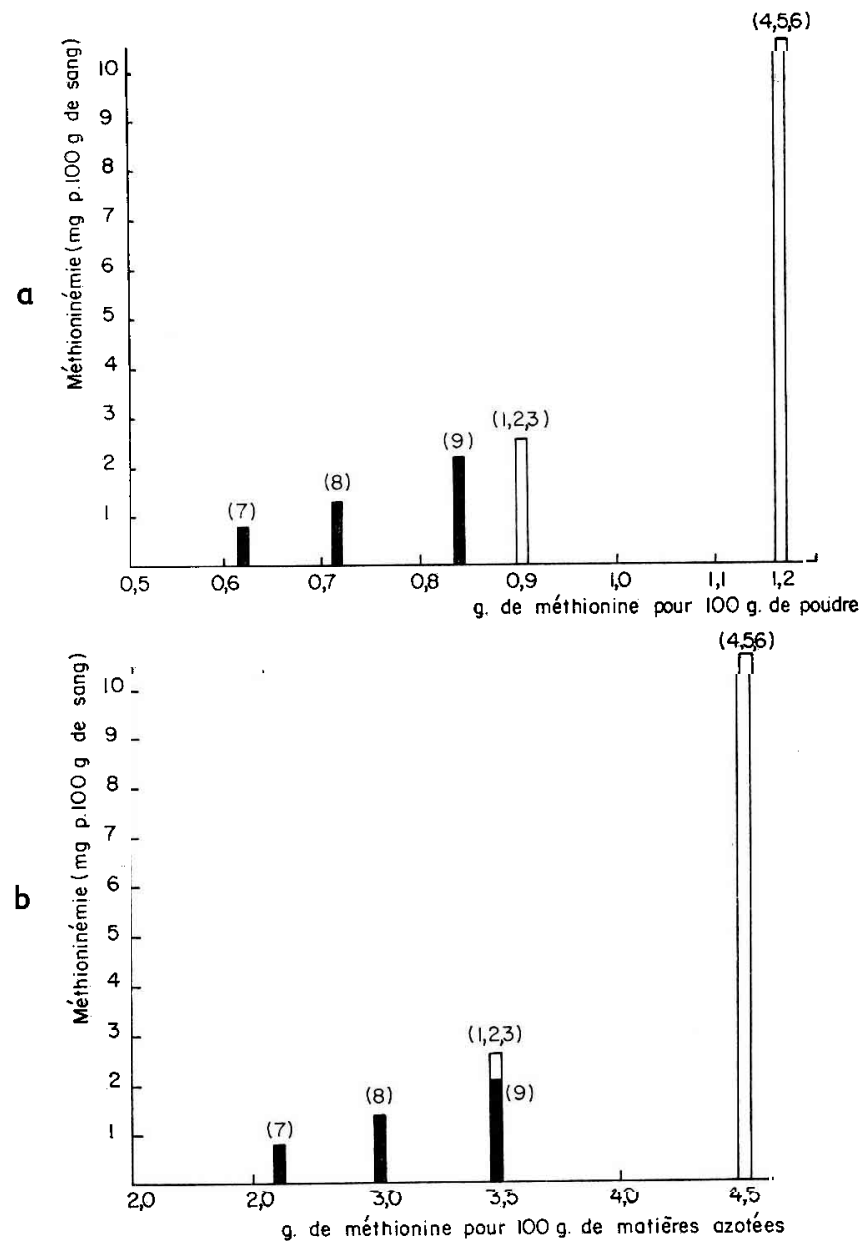

Fig. 4

(7) régimes

le régime contient $9,05 \mathrm{~g}$ de méthionine par $\mathrm{kg}$ de poudre. Cela correspond aux régimes $\mathrm{I}, 2$ et 3 . Il semble plus délicat de déterminer l'équilibre le plus favorable entre les acides aminés puisque la méthioninémie varie selon 1a teneur en matières 
azotées des régimes alors que celles-ci ont la même composition en méthionine $(3,5 \mathrm{~g}$ pour Ioo $\mathrm{g}$ de matières azotées). En effet, si les veaux consommaient les régimes I, 2 ou 3 , contenant $26,4 \mathrm{p}$. Ioo de matières azotées dont 3,5 p. roo étaient de la méthionine, les concentrations sanguines en méthionine étaient voisines de $2,6 \mathrm{mg}$ pour roo $\mathrm{g}$ de sang (tabl. 7 , fig. $4 \mathrm{~b}$ ). S'ils consommaient le régime 9 contenant $24,5 \mathrm{p}$. Ioo de matières azotées, mais dont $3,5 \mathrm{p}$. Ioo étaient aussi de la méthionine, les teneurs en méthionine libre du sang n'étaient que de $2,2 \mathrm{mg} \mathrm{p}$. Ioo $\mathrm{g}$ de sang (tabl. 7 , fig. 4 b). Il semblerait donc que dans le cas de tels régimes, contenant au plus $3,5 \mathrm{~g}$ de méthionine pour Ioo $\mathrm{g}$ de matières azotées, il $\mathrm{y}$ ait une certaine indépendance entre la teneur de la protéine en méthionine et la méthioninémie. Par contre, il existerait une relation beaucoup plus étroite entre la teneur du régime en méthionine et la méthioninémie (fig. 4 a). Cela pourrait signifier que la légère augmentation de la méthioninémie que 1'on observait lorsque les animaux ingéraient moins de $0,58 \mathrm{~g}$ de méthionine par unité de poids métabolique et par jour, ne dépend pas du rapport entre les quantités de méthionine et celles des autres acides aminés indispensables ingérés. Cela est à rapprocher des résultats de PAWLAK et PION (I970) qui ont montré que lorsqu'on augmentait dans un aliment le pourcentage de protéines équilibrées en acides aminés, on observait un léger accroissement de la concentration de la plupart des acides aminés indispensables jibres dans le sang des rats.

On peut aussi se demander si la vitesse de croissance n'est pas un facteur susceptible de modifier l'évolution de la méthioninémie en fonction de la quantité de méthionine ingérée et donc de modifier notre estimation du besoin. Dans le tableau Io, nous avons regroupé l'ensemble des relations entre ces grandeurs pour différentes vitesses de croissance et périodes. Nous remarquons que si le gain moyen journalier

\section{TABLEAU IO}

Relations entre la méthioninémie (Y) et la quantité de méthionine ingérée (X) pour différentes vitesse de croissance et périodes

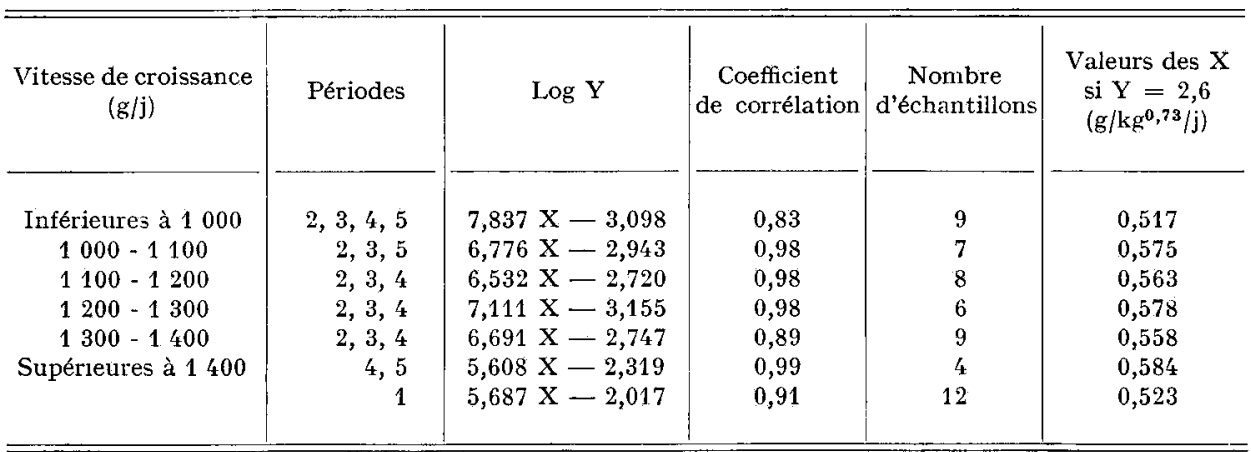

est compris entre I ooo et I $400 \mathrm{~g} / \mathrm{j}$, les relations sont comparables. Nous pensons que cela traduit d'une part, l'étroite liaison qui existe entre la vitesse de croissance et la quantité de poudre ingérée et d'autre part la relative constance de la composition du croît chez des animaux de mêmes âges et ayant des vitesses de croissances 
assez voisines. Au contraire, si les animaux ont des vitesses de croissance très élevées (supérieures à $\mathrm{I} 400 \mathrm{~g} / \mathrm{j}$ ) ou lorsqu'ils sont plus jeunes (période $\mathrm{I}$ ), la concentration en méthionine libre dans le sang s'élèverait moins rapidement. Par contre, si les animaux ne sont pas en première période et s'ils ont des vitesses de croissance faibles (inférieures à $I$ ooo $\mathrm{g} / \mathrm{j}$ )la méthionine libre du sang tend à s'accumuler plus rapidement. Cependant à une méthioninémie de $2,6 \mathrm{mg}$ pour Ioo $\mathrm{g}$ de sang correspondent dans tous les cas, des ingestions de méthionine très voisines de $0,58 \mathrm{~g} / \mathrm{kg}^{0,73} / \mathrm{j}$.

Le besoin du. Veau pré-ruminant en méthionine tel que nous l'avons étudié jusqu'à présent serait donc de $0,5^{8} \mathrm{~g} / \mathrm{kg}^{0,73} / \mathrm{j}$. Il pourrait être satisfait par 1'ingestion de régimes analogues à ceux que nous avons utilisés contenant $9,05 \mathrm{~g}$ de méthionine par $\mathrm{kg}$ de poudre ou $3,5 \mathrm{~g}$ de méthionine pour Ioo $\mathrm{g}$ de matières azotées si le taux protéique de 1'aliment est voisin de $26 \mathrm{p}$. Ioo.

Lors de leur étude du besoin en méthionine du Porcelet, à l'aide d'une méthode comparable à la nôtre, KEITH et al. (I972) obtiennent des résultats semblables. A l'ingestion d'un régime contenant $0,46 \mathrm{p}$. Ioo de méthionine c'est-à-dire $3,6 \mathrm{~g}$ de méthionine pour $\mathrm{I} 6 \mathrm{~g}$ d'azote), correspondent une teneur en méthionine libre sérique voisine de $2,7 \mathrm{mg}$ pour $100 \mathrm{ml}$ et la satisfaction du besoin en méthionine des porcelets.

Par contre, le besoin du Veau ainsi défini serait nettement inférieur à celui du Rat. L'élévation considérable de la méthioninémie lorsque le régime est enrichi en méthionine a déjà été rapportée par différents auteurs. KLAvins (I965), SAUBERLiCh (I96I), SANCHEZ et SWENDSEId (I969), GiRARD, RobIN et JACQUOT (I968), Benevenga et HaRPER (I970) chez le Rat, ont montré que lorsque le régime contenait plus de 2 p. Ioo de méthionine (ou lorsque la méthionine représentait plus de I2 p. Ioo des matières azotées), on observait une augmentation importante de la concentration en méthionine libre du plasma. SNYDERMAN et al. (I968) signalent le même phénomène chez l'Enfant. Mais, lorsque des rats recevaient des régimes équilibrés contenant Io p. Ioo de caséine et supplémentés par $0,3 \mathrm{p}$. Ioo de méthionine (BENEVENGA et HARPER, I970) ou I8 p. IOO de caséine et supplémentés par 0,4 p. Ioo de méthionine (GIRARD et al., I968), ce qui correspond à des régimes dont 5 p. Ioo et 4 p. roo des matières azotées sont dela méthionine, les auteurs observaient des méthioninémies relativement peu élevées, comprises entre I,3 et 2,I mg pour Ioo g de plasma.

Donc si nous sommes en mesure de préciser quelque peu l'intérêt des supplémentations en méthionine des aliments d'allaitement, cela ne nous est pas possible en ce qui concerne la cystine. En effet, aussi bien les paramètres zootechniques que les paramètres biochimiques étudiés n'ont semblé réagir aux supplémentations en cystine.

Nous ne pouvons alors faire que deux hypothèses :

- la première est que le besoin en cystine du Veau pré-ruminant est satisfait par l'apport de $0,9 \mathrm{~g}$ de cystine et dans ce cas le besoin minimal en méthionine serait supérieur à $70 \mathrm{p}$. IOo du besoin en acides aminés soufrés. Cela serait quelque peu surprenant, car chez le Rat, RAo et al. (Ig6I) ont montré qu'il était de 32 p. Ioo tandis que chez le Porc, BAKER et al. (I970) et MitchelL et al. (rg68 a) ont trouvé qu'il serait compris entre $44 \mathrm{p}$. Ioo et 30 p. Ioo selon que pour le déterminer on retenait le critère d'une croissance optimale ou d'un bilan azoté maximal. 
- la seconde, que l'étude de l'aminoacidémie telle que nous l'avons entreprise est insuffisante pour nous permettre de préciser le besoin en cystine du Veau pré-ruminant.

\section{7. - Réserves sur l'interprétation de la courbe d'accumulation de la méthionine dans le sang}

Outre 1'accumulation de la méthionine dans le sang lorsque les veaux consommaient des régimes relativement peu supplémentés en méthionine, il est un certain nombre d'autres faits qui nous conduisent à nous demander si cette accumulation ne reflète pas aussi certaines particularités du métabolisme de la méthionine chez le jeune Veau:

\section{Méthionine alimentaire libre.}

Parce que la méthioninémie est plus étroitement reliée à la quantité de méthionine ajoutée ingérée par jour qu'à la quantité globale de méthionine ingérée par jour, on peut se demander si la méthionine libre du régime n'aurait pas une influence particulière sur la méthioninémie. Il se pourrait que la méthionine libre soit absorbée plus rapidement que la méthionine des protéines de lait dont une fraction importante coagule dans la caillette. La méthioninémie, mesurée 4 et 5 heures après le repas, reflèterait alors essentiellement l'afflux brutal de méthionine libre alimentaire dans le sang.

Nous avons cependant déjà remarqué (Patureau-Mirand, Prugnaud et PIon, I97I) que la méthioninémie restait élevée après un jeûne de 8 heures $(5,33 \mathrm{mg}$ pour roo $\mathrm{g}$ de sang pour un régime apportant $3,95 \mathrm{~g}$ de méthionine pour roo $\mathrm{g}$ de matières azotées) et même après un jeûne de $\mathrm{I} 6$ heures (résultats obtenus au cours de la $5^{\mathrm{e}}$ période de l'expérience I) En outre, selon PION, PRUGNaUd et RÉRAT (I970) chez le Porc, une certaine proportion de la méthionine des protéines de poisson de l'aliment est absorbée dans les mêmes délais que la méthionine libre. De plus, il est possible qu'interviennent deux autres phénomènes pour atténuer les particularités éventuelles du transit de la méthionine ajoutée. D'une part, la méthionine alimentaire libre qui transite avec la fraction soluble de l'aliment se trouve en compétition avec les glucides : glucose et galactose, dont BINGHAM, NEWEY et SMITH (I966) ont montré les effets inhibiteurs sur l'absorption de la méthionine in vitro. Cependant, ces auteurs ne retrouvent pas les mêmes effets in vivo. D'autre part, Paine, Newman et Taylor (I959) ont montré que chez le Poulet, la vitesse d'absorption de la L-méthionine était 3 fois supérieure à celle de la D-méthionine. Or, nous avons supplémenté avec de la DL-méthionine.

Il ne semblerait donc pas que le fait d'apporter la méthionine des supplémentations sous forme libre soit la raison essentielle pour laquelle on observe une liaison particulièrement étroite entre la quantité de méthionine ajoutée aux régimes et la méthioninémie.

\section{Trans-sulfuration.}

La présence, anormale chez le Rat ou le Porc, de cystathionine dans le sang des veaux et l'absence d'influence des supplémentations en cystine sur la méthioninémie, nous conduisent à penser qu'il se pourrait qu'il $\mathrm{y}$ ait chez le jeune Veau 
des particularités dans le catabolisme de la méthionine vers la cystine par l'intermédiaire de la cystathionine (Du VIGNEAUD, BROWN et ChANDLER, I942). Or cette voie peut quantitativement être très importante puisque selon RoSE et WIXOM (I955), environ go p. Ioo de la méthionine ingérée par un homme adulte est transformée en cystine ou cystéine, cela est confirmé par LASTER et al. (1965).

L'existence de cystathionine dans le sang de Veau pourrait indiquer que chez ce jeune bovin, la cystathionase a une faible activité. Cela est peut être à rapprocher des travaux de Sturman et al. (1970) qui ont mis en évidence la présence de quantités anormales de cystathionine dans le foie de foetus humains, d'enfants prématurés ou même nés à terme. Cette accumulation était associée à l'absence de cystathionase dans le foie des foetus et des enfants prématurés. L'activité cystathionasique du foie des enfants nés à terme, était encore très faible ( $\mathrm{I}_{4}$ fois plus faible que celle du foie des adultes). De ces observations, les auteurs tirent l'hypothèse que la cystine pourrait être un acide aminé essentiel pour les enfants prématurés. De plus, cette carence en cystathionase pourrait être responsable de l'hyperméthioninémie rencontrée chez les enfants à qui on donne un régime riche en protéines (HoLt et al., 1968).

Chez les bovins adultes, MUDD et al. (1965) ont montré que l'activité de la cystathionase du foie était 30 fois inférieure à celle observée dans le foie du Rat alors que les activités de la méthionine adénosyl-transférase et de la cystathionine synthétase n'étaient respectivement que 4 et 8 fois plus faibles. De plus, les travaux de Finkeistern (1967) qui précédaient chez le Rat ceux de Sturman et al. (I968) nous indiquent que les activités des enzymes de la voie de la trans-sulfuration sont plus faibles dans le foie du Rat de 6 g que dans celui du Rat de I $^{\circ} \mathrm{g}$. Il se pourrait donc que, chez le jeune bovin, cette voie du catabolisme de la méthionine qui est aussi celle de la synthèse de la cystine soit peu active.

Une carence de l'aliment en vitamine $B_{6}$ pourrait être responsable de la baisse d'activité de la cystathionase (Finkeistein et Chalmers, I970). Toutefois, dans notre expérience, les régimes abondamment supplémentés en méthionine contenaient environ $9,85 \mathrm{mg}$ de vitamine $B_{6}$ par $\mathrm{kg}$ d'aliment, ce qui est voisin du triple du besoin d'un veau de $50 \mathrm{~kg}$ ayant une croissance journalière de $500 \mathrm{~g}$ (GorRILI, 1972). Le besoin en pyridoxine serait donc largement couvert sauf s'il est accru par les fortes supplémentations en méthionine.

L'importance relativement faible de la trans-sulfuration dans le métabolisme de la méthionine serait plutôt une caractéristique de l'âge et de l'espèce des animaux.

Enfin, il se peut que nous observions une accumulation préférentielle de D-méthionine. Celle-ci est peu catabolisée suivant la voie de la cystéine puisque la $L_{\text {-allo- }}$ cystathionine résultant de la combinaison de la D-homocystéine et de la $\mathrm{L}_{\text {-sérine }}$ ne se scinde pas pour donner de la cystéine (ANSLOw et Du VIGNEAUd, I947, Anslow, Stammonds et Du Vigneaud, I946). Toutefois Wretrind et Rose (1955) ont montré que le Rat utilisait avec sensiblement autant d'efficacité la D-méthionine que la L-méthionine. En fait, l'efficacité des 2 isomères bien que voisine dépendrait cependant du niveau de la supplémentation (ALMOUIST, 1970).

La présence d'anomalies dans le catabolisme de la méthionine vers la cystine expliquerait que le besoin en méthionine du Veau, tel qu'on l'apprécie par l'intermédiaire de la méthioninémie soit relativement bas. De plus, cela nous permet de mieux saisir l'absence de répercussion des supplémentations en cystine sur la méthioninémie. En effet, la cystine dont Kato et al. (1964) et FinKelstern et 
MudD (I967) ont montré l'action inhibitrice in vitro sur la cystathionine synthétase, interviendrait seulement pour ralentir l'activité des enzymes d'une voie métabolique déjà peu active. Enfin, cela impliquerait, chez le Veau, l'existence d'un besoin spécifique en cystine.

\section{8. - Relation entre la méthionine et les autres acides aminés libres du sang}

Contrairement aux résultats de KI,AVINS (I968), BENEVENGA et HARPER (I970) et en accord avec ceux de GIRARD et al. (I968) chez le Rat nous n'avons pas noté de diminution de la teneur du sang en glycine et en sérine, lorsque les veaux consommaient les régimes les plus riches en méthionine. Cela pourrait peut-être signifier qu'une des voies du catabolisme de la méthionine est moins active que chez le Rat. En effet, chez cet animal BENEVENGA et HARPER (I970) ont montré que l'addition de 3 p. IOO de glycine ou de $4,2 \mathrm{p}$. Ioo de sérine à un régime contenant Io $\mathrm{p}$. Ioo de caséine et supplémenté par $3 \mathrm{p}$. Ioo de méthionine faisait baisser la méthioninémie et que simultanément, il y avait un catabolisme oxydatif plus intense de la méthionine.

L'ingestion de quantités importantes de méthionine ou de leucine provoque une augmentaion de la quantité de corticostérone du sang (MUNRo et MUKERJI, I962 ; Munro et al., I965; Peretianu, I968). Or, sous l'action des corticostéroïdes, il y a augmentation du pool des acides aminés libres du muscle par ralentissement de la synthèse protéique dans ce tissu. Cela s'accompagne d'un afflux des acides aminés libres du muscle vers le foie dont l'activité a été stimulée par la corticostérone (MunRo, I970). Comme le lait est très riche en leucine, il se peut que cela ait favorisé la réponse des corticosurrénales aux supplémentations en méthionine. Une augmentation de la concentration en corticostérone du sang lorsque la teneur du régime en méthionine passe de $2,6 \mathrm{~g}$ à $4,5 \mathrm{~g}$ pour Ioo $\mathrm{g}$ de matières azotées expliquerait l'élévation de la concentration sanguine de la plupart des acides aminés à 1'exception des acides aminés à chaîne ramifiée.

L'aptitude du muscle à cataboliser les acides aminés à chaîne ramifiée (MrmurA et al., I968) pourrait rendre compte du comportement particulier de ces composés. De plus, WELLERS et al. (I97I) ont montré chez des rats traités par des doses physiologiques de cortisone que le catabolisme in vivo de la valine libre était $\mathbf{I , 7 5}$ fois plus intense que chez les témoins.

Enfin, les urémies relativement élevées des veaux recevant les régimes les plus riches en méthionine pourraient, elles aussi, refléter l'influence de la corticostérone sur le métabolisme azoté des veaux les plus jeunes.

Nous pensons donc qu'un des effets de la supplémentation en méthionine des aliments d'allaitement riches en leucine serait de favoriser la production de corticostérone. Cela pourrait avoir certaines répercussions sur le métabolisme général des animaux. Cette hypothèse devrait pouvoir être vérifiée, notamment par le dosage de la corticostérone sanguine.

\section{CONCLUSION}

Malgré les réserves que nous avons pu émettre sur la signification physiologique de la courbe d'accumulation de la méthionine dans le sang, nous avons montré l'intérêt de la technique employée. Elle nous a permis de discuter différents points de 
méthodologie, en particulier, l'effet du traitement de la période précédente sur les paramètres étudiés pendant la période en cours. Nous avons dû aussi nous interroger sur les problèmes que soulevait l'utilisation de DL-méthionine libre pour supplémenter les aliments d'allaitement. De plus, nous avons vu que le besoin en méthionine du Veau pré-ruminant semblerait être proche de $3,5 \mathrm{~g}$ pour Ioo $\mathrm{g}$ de matières azotées alimentaires contenant au moins $0,9 \mathrm{~g}$ de cystine. Cependant, des études du métabolisme du soufre de la méthionine sembleraient utiles pour préciser les relations entre les acides aminés soufrés chez le Veau pré-ruminant ainsi que les besoins en cystine de cet animal. Enfin, l'étude de la concentration des autres acides aminés du sang, nous a permis de mettre en évidence un éventuel effet annexe des supplémentations excessives en méthionine sur le métabolisme du Veau.

Reçu pour publication en décembre 1972.

\title{
REMERCIEMENTS
}

Nous tenons à remercier M.-M. C. Michel qui a bien voulu effectuer les dosages d'urée.

\section{SUMMARY}

\author{
INFLUENCE OF SULPHUR AMINO ACID SUPPLEMENTATION \\ OF A MILK REPLACER ON BLOOD-FREE AMINO ACID LEVELS \\ METHIONINE REQUIREMENT OF THE PRERUMINANT CALF
}

Two experiments were carried out to study the effect of sulphur amino acid supplementation on blood-free amino acid levels of the pre-ruminant calf. In experiment $\mathrm{I}$, six calves (A to $\mathrm{F}$ ) were fed a practical milk replacer $(26,4$ p. Ioo milk protein) containing 2 graded levels of methionine and 3 graded levels of cystine (diets I to 6) during four ro-days feeding periods (tabl. 2). In experiment 2 , six calves were assigned to 2 experimental groups $\left(A^{\prime}\right.$ and $\left.B^{\prime}\right)$ on the basis of weight $(53,0 \mathrm{~kg}$ and $53,6 \mathrm{~kg}$ respectively). They were fed a practical milk replacer $(24,5$ p. roo milk protein) containing 3 graded levels of methionine during five I4-days feeding periods (tabl. 2). In order to determine uremia and blood-free amino acid contents, jugular blood samples were drawn 4 and 5 hours after the morning meal on the last two days of each period.

The sulphur amino acid supplementation had no significant effect on growth and food intakes (tabl. 4, 5). No effect of the cystine supplementations on blood-free amino acids was noticed. Methioninemia measured at the end of a period resulted from the methionine supplementation level during this period (tabl. 7) ; it did not depend on the diet fed during the preceding period (tabl. 9). There was a better correlation between the ingested amount of crystalline DL-methionine and blood methionine than between the ingested amount of total methionine and methioninemia (fig. 2,3). There was a large increase of free methionine content in blood when amount of total ingested methionine exceded $0,58 \mathrm{~g} / \mathrm{kg}{ }^{0.73} / \mathrm{d}$. It may be inferred from this fact that the methionine requirement of our animals seemed to be close to $0,58 \mathrm{~g} / \mathrm{kg} 0.73 / \mathrm{d}$; that means that the diet should contain $9 \mathrm{~g}$ methionine per $\mathrm{kg}$ milk replacer powder or $3.5 \mathrm{~g}$ methionine p. $16 \mathrm{~g} \mathrm{~N}$, if protein diet content is $26.4 \mathrm{p}$. Ioo. An increase of urea and of most, free amino acids in blood was observed when calves were fed the high methionine diets (diets $4,5,6$ ) (tabl. 6, 8). A possible adrenal corticosteroid discharge correlated to this high methionine intake is discussed. 


\section{RÉFÉRENCES BIBLIOGRAPHIQUES}

Almouist H. J., I970. in MUTH O. H., OLdFIELD J. E. Symposium: Sulfur in nutrition. AVI publishing Company Inc. Westport Connecticut.

Anslow W. P., Simmonds S., Du Vigneaud V., i946. Cités par Greenstein J. P. et Winitz M., I96r. Chemistry of the amino acids, 1, p. 324 .

Anslow W. P., Du Vigneaud V., i947. Cités par Greenstein J. P. et Winitz M., rg6r. Chemistry of the amino acids, 1, p. 324 .

Baker D. H., Clausing W. W., Harmon B. G., Jensen A. H., Becker D. E., I97o. Replacement value of cystine for methionine for the young pig. J.Anim. Sci., 29, 581-584.

Benevenga N. J., Harper A. E., I970. Effect of glycine and serine on methionine metabolism in rats fed diets high in methionine. $J$. Nutr., 100, 1205-1214.

Bingham K. J., NewEy H., SMYTH D. H., Ig66. Interaction of sugars and amino acids in intestinal transfer. Biochim. Biophys. Acta, 130, 281-284.

Blaxter K. L., WoOD W. A., 1952. The nutrition of the Ayrshire calf 7. The biological value of gelatin and of casein when given as the sole source of protein. Br.J. Nutr., 6, 56-7I.

Du Vigneaud V., Brown G. B., Chandler J. P., 1942. Cités par Greenstein J. P. et Winitz. M.. I961. Chemistry of the amino acids, 1, p. 323 .

Fauconneau G., I967. Quelques aspects actuels de la nutrition azotée des animaux monogastriques. 9th Internat. Congr. Anim. Prod. Oliver and Boyd Edinburg, p. 52.

Finkelstein J. D., I967. Methionine metabolism in mammals. Effect of age, diet and hormones on three enzymes of the pathway in rat tissues. Arch. Biochem. Biophys., 122, 583-590.

Finkelstein J. D., MUdD S. H., I967. Trans-sulfuration in mammals. The methionine sparing effect of cystine. J. Biol. Chem., 242, 873-88o.

Finkelstein J. B., Chalmers F. T., 1970. Pyridoxine effects on cystathionine synthetase in rat liver. J. Nutr., 100, 467-469.

Girard A., Robin P., Jacquot R., rg68. Effets d'une surcharge alimentaire de méthionine sur la teneur du plasma en amino-acides libres et en certains de leurs dérivés. Étude sur le rat en croissance. C. R. Acad. Sci. Paris., 266, D, 2160-2I63.

Gorrill, A. D. L., 1972. in CHURCH D. C., Digestive physiology and mutrition of ruminants, 3, Practical mutrition, p. 97. Oregon state University. Corvallis Oregon.

Greenstein J. P., Winitz M., I96i. Chemistry of the amino acids. 1, p. 760 . John Wiley and Sons, Inc New York.

Holt L. E., Snyderman S. E., Norton P. M., Roitman E., Ig68. In Leathem J. H., Protein nutrition and free amino acid patterns 272-30 Rutgers. University Press New Brunswick N. J.

Kato A., Matsuzaka T., Suda M., Nakagawa H., Ishizuka J., I964. Control mechanism in the rat liver enzyme system converting L-methionine to L-cystine. I. Enzymatic basis for the methionine sparing action of L-cystine. J. Biochem., 55, 40r-409.

Keith M. O., Christensen D. A., Owen B. D., I972. Determination of the methionine requirement of growing pigs using serum free amino acids. Can. J. Anim. Sci., 52, 163-169.

KLavins J. V., 1965. Pathology of amino acid excess. V. Effect of methionine on free amino acids in serum. Biochim. Biophys. Acta, 104, 554-565.

Laster L., Mudd S. H., Finkelstein J. D., Irrevere F., ig65. Homocystinuria due to cystathionine synthetase deffciency. The metabolism of L-methionine. J. Clin. Invest., 44, I708-1718.

Mc Laughlan J. M., Illman W. I., 1967. Use of free plasma amino acid levels for estimating amino acid requirements of the growing rat. $J$. Nutr., 93, 2I-24.

Mitchell J. R., Becker D. E., Harmon B. G., Norton H. W., Jensen A. H., Ig68 a. Some amino acid needs of the young pig fed a semi synthetic diet. J. Anim. Sci., 27, 1322-I326.

Mitchell J. R., Becker D. E., Jensen A. H., Harmon B. G., Norton H. W., ig68 b. Determination of amino acid needs of the young pig by nitrogen balance and plasma free amino acids. $J, A$ nim Sci., 27, 1327-135I.

Mimura T., Yamada C., Swendseid M. E., I968. Influence of dietary protein levels and hydrocortisone administration on the branched chain amino acid transaminase in rat tissues. $J . N u t r$, 85, 493498.

Moore S., Spackman D. H., Stein H. W., r958. Chromatography of amino acids on sulfonated polystyrene resins. Analyt. Chem., 30, I I85-I I90.

Mudd S. H., Finkelstein J. D., IrRevere F., Laster L., I965. Transsulfuration in mammals. Micro-assays and tissue distributions of three enzymes of the pathway, J. Biol. Chem., 240, 4382-4392.

Munro H. N., MukerJI D., I962. The mechanism by which administration of individual amino acids causes changes in ribonucleic and metabolism of the liver. Biochem. J., 82, 520-522. 
Munro H. N., Steele M. H., Hutchinson W. C., I965. Action of dietary proteins and amino acids on the adrenal gland. Brit. J. Nutr., 19, 137-147.

Munro H. N., I97o. Free amino acid pools and their regulation in Munro H. N., I970. Mammalian Protein metabolism, 4, p. 359. Academic Press, N.-Y.

ODoRico G., I969. Los amino acids de sintesis en los leches artificiales para cebo de terneros. Zootechnia., 18, 29-38.

Paine C. M., Newman N. J., TAYlor M. W., I959. Intestinal absorption of methionine and histidine by the chicken. Am. $\vec{J}$. Physiol., 197, 9-I2.

Patureau-Mirand P., Prugnaud J., Pion R., i971. Influence de la nature des protéines des aliments d'allaitement sur l'aminoacidémie libre du veau pré-ruminant. $X \mathrm{e}$ Congr. Internat. Zootech. Versailles.

Pawlak M., Pion R., Ig68a. Influence de la supplémentation des protéines du blé par des doses croissantes de thréonine sur les teneurs en acides aminés libres du sang total et du muscle du rat en croissance. C. R. Acad. Sci., 266, D I993-1995.

PAWLAK M., Pion R., Ig68 b. Influence de la supplémentation des protéines du blé par des doses croissantes de lysine sur la teneur en acides aminés libres du sang et du muscle du rat en croissance. Ann. Biol, anim. Bioch. Biophys., 8, 517-530.

Pawlak M., Pion R., I97o. Utilisation des acides aminés du tournesol pour la croissance du rat. Influence du taux protéique de la ration sur les teneurs en acides aminés libres du sang et du muscle. Ann. Biol. anim. Bioch. Biophys., 10, 317-322.

Peretianu J., rg68. Teneur en costicostérone du sang et des surrénales chez le rat nourri avec un régime contenant un excès en méthionine. Arch. Sci. Physiol., 22, 44I-447.

Pion R., Fauconneau G., RÉrat A., Ig64. Variation de la composition en acides aminés du sang porte au cours de la digestion chez le porc. Ann. Biol. anim. Bioch. Biophys., 4, 383-40I.

Pion R., Prugnaud J., Rérat A., I97o. Étude cinétique de la supplémentation de la farine de poisson par la DL-méthionine chez le porc en croissance. Journées de la Recherche Porcine en France A. F. Z. 67-73.

Porter J. W. G., Hill W. B., 1964. Nitrogen balance trials with calves given synthetic milk diets. Ann. Rep. Nat. Inst. Res. Dairying, p. 124.

Rao R., Norton H. W., Johnson B. C., I96I. The amino acid composition and nutritive value of proteins. IV. Phenylalanine, tyrosine, methionine and cystine requirements of the growing rat. J.Nutr. 73, 38-42.

RoBERT J.-C., I97I. Supplémentation en acides aminés des aliments d'allaitement. Ind. alim. animale, 6, Ir-28.

Rose W. C., Wıхом R. L., 1955. The amino acid requirements of man. XIII. The sparing effect of cystine on the methionine requirement. J. Biol. Chem., 216, 763-773.

Sanchez A., Swendseid M. E., 1969. Amino acid levels and enzyme activity in tissues of rat force-fed diets differing in methionine content. $J$. Nutr., 98, I45-I5I.

SaUberlich H. E., I96r. Studies on the toxicity and antagonism of amino acids for weanling rats. $J$. Nutr., 75, 6r-72.

Snyderman S. E., Holt L. E. Jr., Norton P. M., Roitman E., I968. In Leathem J. H. Protein nutrition and free amino acid patterns, I9-31. Rutgers University Press. New Brunswick N. J.

Sturman J. A., Gaull G., Raiha N. C. R, I97o. Absence of cystathionase in human fetal liver : is cystine essential? Science, 169, I74-ז76.

TARVER H., Schmidt C. L. A., I939. The conversion of methionine to cystine : experiments with radioactive sulfur. J. Biol. Chem., 130,67-80.

Toullec R., Mathiev C.-M., I97I. Utilisation digestive de matières grasses par le veau pré-ruminant à l'engrais : influence du taux d'incorporation dans les aliments d'allaitement. Ann. Zootech., 20, 247-250.

Weliers G., Chevan J., Galent N., I97I. Influence de la cortisone sur la vitesse de dégradation irréversible in vivo de la valine libre. C. $R$. Acad. Sci., 272, D I882-1885.

Womack M., Kemmerer K. S., Rose W. C., 1937. Cités par Greenstein J. P. et Winitz M., I96r. Chemistry of the amino acids, 1 p. 72.

WretLind K. A. J., Rose W. C., I95o. Methionine requirement for growth and utilization of its optical isomers. J. Biol. Chem., 187, 697-703.

Young V. R., Hussein M. A., Murray E., Scrimshaw N. S., I97I. Plasma tryptophan responsecurve and its relation to tryptophan requirements in the young adult man. J. Nutr., 101, 45-6o. 